\title{
Estimation neutre
}
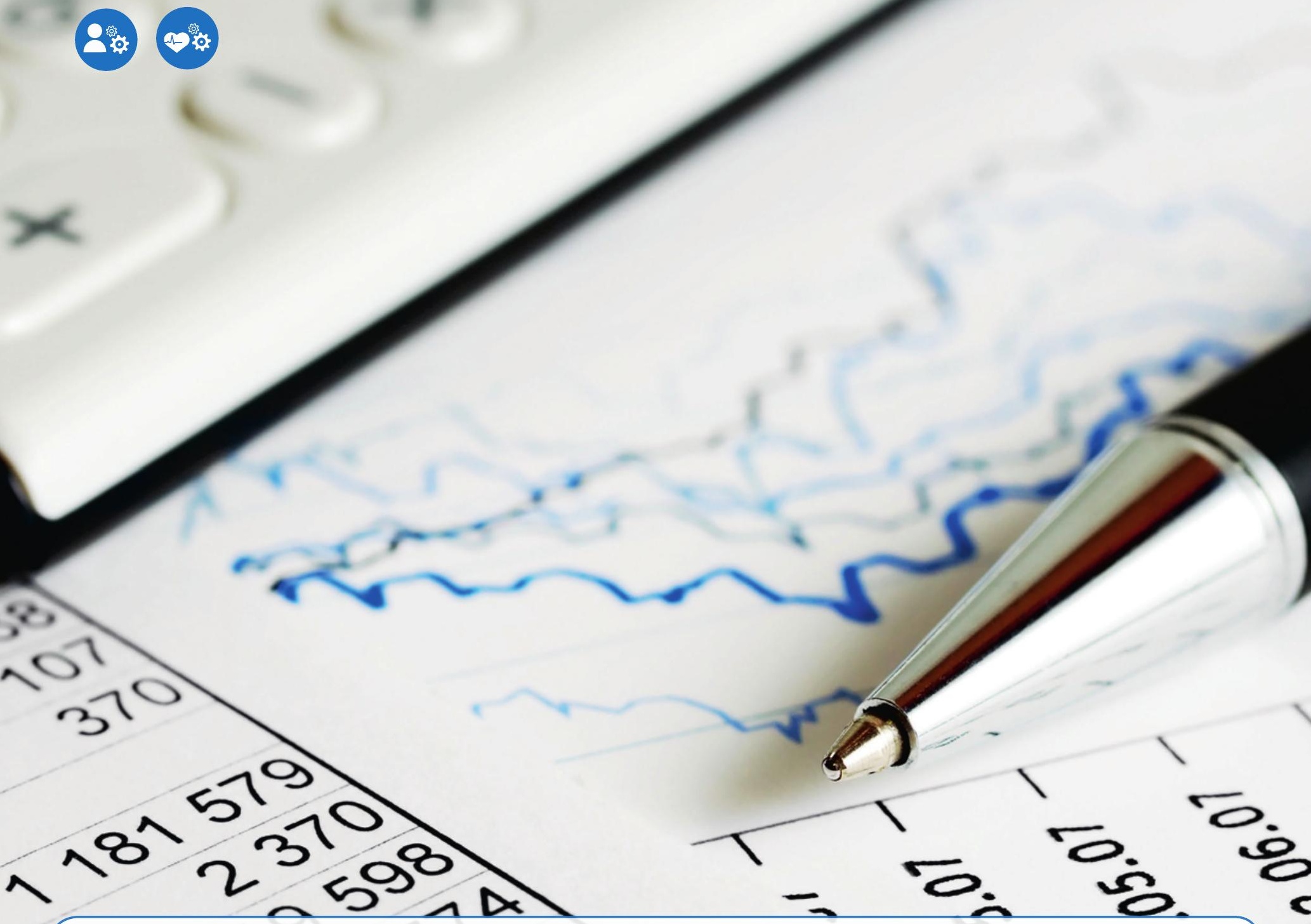

En cas d'arrivée, de départ, de recherche ou de séparation d'un associé du cabinet:

- Estimation neutre de l'entreprise (inventaire, goodwill, valeur des actions)

- Rapport qualité-prix attrayant

- Leader sur le marché, longue expérience et compétences largement reconnues dans l'estimation de tous types de cabinets médicaux

\section{ESTIMATION NEUTRE

Vous pouvez prendre contact avec nous sans aucune obligation par téléphone ou courrier électronique ou en nous retournant le talon-réponse par fax ou par la Poste. Nous vous contacterons.

Prénom / nom

Adresse

NPA / lieu

Téléphone privé / prof.

Atteignable de préférence vers

Adresse mail

\section{CONSULTING}

FMH Consulting Services AG

Avenue d'Ouchy 66, 1006 Lausanne

Tél. 0219224435

mail@fmhconsulting.ch - www.fmhservices.ch 